\title{
Osteogenic induction of hBMSCs by electrospun scaffolds with dexamethasone release functionality
}

\author{
Albino Martins ${ }^{\mathrm{a}, \mathrm{b}, *}$, Ana Rita C. Duarte ${ }^{\mathrm{a}, \mathrm{b}}$, Susana Faria ${ }^{\mathrm{c}}$, Alexandra P. Marques ${ }^{\mathrm{a}, \mathrm{b}}$, Rui L. Reis ${ }^{\mathrm{a}, \mathrm{b}}$, \\ Nuno M. Neves ${ }^{\mathrm{a}, \mathrm{b}}$

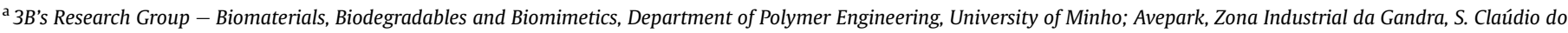 \\ Barco, 4806-909 Caldas das Taipas, Guimarães, Portugal \\ ${ }^{\mathrm{b}}$ IBB - Institute for Biotechnology and Bioengineering, PT Government Associated Laboratory, Braga, Portugal \\ ${ }^{\mathrm{c}}$ Department of Mathematics and Applications, Mathematical Research Centre CMAT, University of Minho, Campus de Azurém, 4800-058 Guimarães, Portugal
}

\section{A R T I C L E I N F O}

\section{Article history:}

Received 23 February 2010

Accepted 5 April 2010

Available online 10 May 2010

\section{Keywords:}

Drug release

Polycaprolactone

Mesenchymal stem cells

Bone tissue engineering

Molecular biology

\begin{abstract}
A B S T R A C T
Electrospun structures were proposed as scaffolds owing to their morphological and structural similarities with the extracellular matrix found in many native tissues. These fibrous structures were also proposed as drug release systems by exploiting the direct dependence of the release rate of a drug on the surface area. An osteogenic differentiation factor, dexamethasone (DEX), was incorporated into electrospun polycaprolactone (PCL) nanofibers at different concentrations $(5,10,15$ and $20 \mathrm{wt}$.\% polymer), in a single-step process. The DEX incorporated into the polymeric carrier is in amorphous state, as determined by DSC, and does not influence the typical nanofibers morphology. In vitro drug release studies demonstrated that the dexamethasone release was sustained over a period of 15 days. The bioactivity of the released dexamethasone was assessed by cultivating human bone marrow mesenchymal stem cells (hBMSCs) on 15 wt.\% DEX-loaded PCL NFMs, under dexamethasone-absent osteogenic differentiation medium formulation. An increased concentration of alkaline phosphatase and deposition of a mineralized matrix was observed. Phenotypic and genotypic expression of osteoblastic-specific markers corroborates the osteogenic activity of the loaded growth/differentiation factor. Overall data suggests that the electrospun biodegradable nanofibers can be used as carriers for the sustained release of growth/differentiation factors relevant for bone tissue engineering strategies.
\end{abstract}

(c) 2010 Elsevier Ltd. All rights reserved.

\section{Introduction}

Drug release systems are used to improve the therapeutic efficacy and safety of drugs, and enhancing the quality of life of patients, by delivering them to the site of action at a rate dictated by the need of the physiological environment [1]. The limitations of the current drug release systems include suboptimal availability, limited effective targeting and potential cytotoxicity resulting from deficient control of the release kinetics. Nanoscale drug release systems can be designed to tune the release kinetics, to regulate distribution and to minimize toxic side effects, thereby enhancing the therapeutic efficacy of a given drug. Drug release with polymer nanofibers is based on the principle that the dissolution rate of a drug increases with increased surface area of both the drug and

\footnotetext{
* Corresponding author: 3B's Research Group - Biomaterials, Biodegradables and Biomimetics, Department of Polymer Engineering, University of Minho; Avepark, Zona Industrial da Gandra, S. Claúdio do Barco, 4806-909 Caldas das Taipas, Guimarães, Portugal. Tel.: +351 253 510900; fax: +351 253510909.

E-mail address: amartins@dep.uminho.pt (A. Martins).
}

the corresponding carrier [2]. Unlike common encapsulation systems involving some complex preparation process [3], electrospinning allows the convenient incorporation of therapeutic/ bioactive compounds into the carrier polymer nanofibers in a single-step process [4]. Indeed, it was observed that enzymes and antibiotics encapsulated in electrospun nanofibers preserved higher catalytic activity than the ones incorporated in solvent casting membranes [5,6].

Electrospinning is considered a promising and versatile processing technique, since several polymeric systems [7,8], proteins [9,10] and even living cells [11] can be applied to develop functionally active nanofibrous structures. Recently, electrospun nanofibers were used as a carrier for both hydrophobic and hydrophilic drugs [6,12-14], where the drug release profile can be controlled by the modulation of scaffold morphology, porosity, and composition. In general, the incorporation of bioactive materials (i.e. proteins and growth factors) within electrospun fibers is achieved by "twophase" electrospinning, where an aqueous solution of the biological molecule is mixed with an organic polymeric solution to form a biphasic suspension [10,15-17], resulting in the encapsulation of 
aqueous reservoirs within the polymer fibers. In another possible alternative, two or more components can be co-electrospun through coaxial capillary channels and integrated into the core-shell biphasic fibrous structure [8]. That strategy leads to difficulties in controlling the kinetics of release of those bioactive molecules, including the burst release effect [18-20]. So far, the research has been directed to obtain the controlled release of anti-inflammatory agents, antibiotics and anticancer agents [21]. The controlled release of growth and differentiation factors from electrospun meshes was not previously explored.

Functional and structural engineering of musculoskeletal tissue, using a tissue engineering approach, may involve the use of appropriated cells cultured with specific growth factors after seeding in biomaterial scaffolds. Controlled release of therapeutic/ bioactive molecules from biodegradable scaffolds will enhance the efficacy of tissue engineering approaches [1]. In fact, polymeric biomaterials are frequently used as release systems, since they can readily deliver growth factors at the desired site either by direct protein release approaches or indirectly by gene therapy or by cell transplantation [22]. Consequently, herein we propose the development of electrospun biodegradable nanofibers as a release system of an established osteogenic differentiation factor - dexamethasone - of mesenchymal stem cells (MSCs). Dexamethasone (DEX) is a synthetic glucocorticoid, which has been shown to stimulate MSCs proliferation and to support osteogenic lineage differentiation in vitro, together with $\beta$-glycerophosphate and ascorbic acid, in defined concentrations [23,24]. $\beta$-glycerophosphate, the organic phosphate source, plays an important role in the mineralization process and in modulating osteoblast activities, such as the alkaline phosphatase (ALP) activity and in the expression of osteocalcin. Moreover, ascorbic acid is also essential for increasing cell viability and to stimulate the production of Collagen type I by osteogenic cells. Therefore, the in vitro osteogenesis of MSCs might be more successfully established if the culturing substrate/scaffold combines at its surface the adequate physical (i.e. ECM-like nanofibers) and chemical (i.e. growth/ differentiation factors) stimulus. Ultimately, we aim at improving the efficacy and reduce the total time required to regenerate a functional bone tissue.

Other authors in the literature reported on electrospun silk fibroin composite fiber scaffolds, containing bone morphogenetic protein-2 (BMP-2) and/or nanoparticles of hydroxyapatite (nHAP), and cultured them with human bone marrow-derived mesenchymal stem cells (hBMSCs) [25]. The results demonstrated that those scaffolds, not only support growth and osteogenic differentiation of hBMSCs, but significantly enhance calcium deposition and mRNA transcript levels of bone-related genes. Recently, in a similar work [26], recombinant human bone morphogenetic protein-2 (rhBMP-2) was loaded into poly(D,L-lactide-co-glycolide)/ hydroxylapatite (PLGA/HAp) composite electrospun fibrous scaffolds. Cell culture experiments with BMSCs showed that the encapsulation of HAp could enhance cell attachment to scaffolds and lower cytotoxicity effect. Both works described electrospun fibrous as release system incorporating a growth/differentiation factor with known clinical potential (FDA approved) for bone and cartilage repair [27]. However, the required cocktail of BMPs able to induce a controlled osteogenic differentiation of mesenchymal stem cells is still to be defined.

\section{Materials and methods}

2.1. Production of nanofiber meshes loaded with dexamethasone

A polymeric solution of poly( $\varepsilon$-caprolactone) (PCL) (TONE ${ }^{\mathrm{TM}}$, Union Carbide Chemicals and Plastics Division, New Jersey) $17 \%$ (w/v) was prepared using a mixture of chloroform and dimethylformamide (7:3), as described elsewhere [28]. Different quantities (5, 10, 15 and 20 wt.\% polymer) of dexamethasone (Sigma-Aldrich, Germany) were added to the polymeric solution previously prepared, and let to stir until complete dissolution was achieved (approximately during $20 \mathrm{~min}$ ). A tension of $9.5 \mathrm{kV}$, a current of $3.32 \mu \mathrm{A}$, a needle tip-to-ground collector distance of $20 \mathrm{~cm}$ and a flow rate of $1 \mathrm{~mL} / \mathrm{h}$ were defined as optimized processing conditions for the specific material being processed.

\subsection{Characterization of dexamethasone-loaded PCL nanofiber meshes}

DEX-loaded electrospun PCL nanofiber meshes were gold sputter-coated (model SC502, Fisons Instruments, England) for $2 \mathrm{~min}$ at $15 \mathrm{~mA}$. Samples were analyzed using a Scanning Electron Microscope (model S360, Leica Cambridge, England). Micrographs were recorded at $15 \mathrm{kV}$ with magnifications ranging from 100 to 5000 times.

Fourier Transform Infra-Red Spectroscopy (FTIR) analysis was performed with the DEX-loaded electrospun PCL nanofiber meshes. The samples were powdered, mixed with $\mathrm{KBr}$, and processed into pellets. FTIR spectra were recorded at 48 scans with a resolution of $2 \mathrm{~cm}^{-1}$ (Shimadzu - IR Prestige 21)

Differential Scanning Calorimetry (DSC) experiments were carried out using a DSC 0100 equipment (TA Instruments - ELNOR). The experiments were conducted under a nitrogen atmosphere on samples (5-10 $\mathrm{mg}$ ) packed in aluminium capsules. The samples were heated in two stages at a constant heating rate of $10^{\circ} \mathrm{C} / \mathrm{min}$ from room temperature up to $300{ }^{\circ} \mathrm{C}$. The samples were kept at this temperature for a period of $2 \mathrm{~min}$ and cooled at the same rate to the initial temperature.

\subsection{Dexamethasone kinetic release studies}

DEX-loaded PCL nanofiber meshes (with $4 \mathrm{~cm}^{2}$ ) were weighted and incubated at $37^{\circ} \mathrm{C}$ in $30 \mathrm{~mL}$ of phosphate buffer solution stirred at $60 \mathrm{rpm}$. Aliquots of $3 \mathrm{~mL}$ were retrieved in predetermined time intervals and the same volume of fresh medium was added to the suspension. The samples were analyzed by UV-Vis spectroscopy at $242 \mathrm{~nm}$ (Shimazu UV 1601). The DEX concentration of each sample was calculated using a standard curve (concentrations ranging from 0.0 to $72 \mu \mathrm{g} / \mathrm{mL}$ ), relating the quantity of DEX with the intensity of light absorbance. The results presented are an average of three measurements. Calculations of the amount of drug released took into account the replacement of aliquots with fresh medium. Unloaded control PCL nanofiber meshes (PCL NFMs) were considered as blanks in the performed quantification.

\subsection{Expansion, seeding and osteogenic differentiation of human bone marrow mesenchymal stem cells}

Human bone marrow mesenchymal stem cells (hBMSCs) (Biopredic International, France) were isolated and characterized according to the method established by Delorme and Charbord [29]. hBMSCs were expanded in basal medium consisting of MEM alpha medium ( $\alpha$-MEM; Gibco, GB) supplemented with $10 \%$ heat-inactivated fetal bovine serum (FBS; Biochrom AG, Germany) and 1\% antibiotic/antimyotic solution (final concentration of penicillin 100 units/mL and streptomycin $100 \mu \mathrm{g} / \mathrm{mL}$ Gibco, GB). Cells were cultured at $37{ }^{\circ} \mathrm{C}$ in an atmosphere of $5 \% \mathrm{CO}_{2}$.

Before the in vitro studies, PCL nanofiber meshes loaded with 15 wt.\% dexamethasone were cut in samples with areas of approximately $1 \mathrm{~cm}^{2}$ and sterilized by UV irradiation during $1 \mathrm{~h}$ on each side of the mesh. Confluent hBMSCs at passage 4 were harvested for seeding onto the DEX-loaded PCL NFMs at a density of $1.0 \times 10^{5}$ cells $/ \mathrm{cm}^{2}$ of the nanofiber mesh. Unloaded PCL nanofiber meshes were used as controls. The DEX-loaded PCL NFMs-hBMSCs constructs were cultured under static conditions, in basal and dexamethasone-absent osteogenic differentiation media (basal medium supplemented with $50 \mu \mathrm{g} / \mathrm{mL}$ ascorbic acid and $10 \mathrm{mM}$ $\beta$-glycerophosphate). The control PCL NFMs-hBMSCs constructs were also cultured under static condition, in basal and standard osteogenic differentiation media (basal medium supplemented with $50 \mu \mathrm{g} / \mathrm{mL}$ ascorbic acid, $10 \mathrm{~mm} \beta$-glycerophosphate and $10^{-7} \mathrm{M}$ dexamethasone). The constructs were retrieved at different culture times: 7 , 14 and 21 days.

\subsection{Cell morphology and distribution, and chemistry of deposited matrix}

For scanning electron microscopy (SEM) observation, the samples were fixed with $2.5 \%$ Glutaraldehyde (Sigma; USA) in a Phosphate Buffer Saline solution (Sigma; USA) during $1 \mathrm{~h}$ at $4{ }^{\circ} \mathrm{C}$. The samples were further dehydrated through increasing series of ethanol concentrations and let to dry overnight. Previous to the analysis by SEM (model S360, Leica Cambridge, England) equipped with an energy dispersive spectrometer (EDS; link-eXL-II), the samples were gold or carbon sputtercoated (sputter coater model SC502, Fisons Instruments, England).

\subsection{Cell viability and proliferation assessment}

Cell viability for each culturing time was determined using the CellTiter $96^{(\mathbb{R}}$ AQueous One Solution Cell Proliferation Assay (Promega, USA). This assay is based on the bioreduction of a tetrazolium compound, 3-(4,5-dimethylthiazol-2-yl)-5-(3-carboxymethoxyphenyl)-2-(4-sulfofenyl)-2H-tetrazolium [MTS], into a water-soluble 
brown formazan product. The absorbance was measured at $490 \mathrm{~nm}$ in a microplate reader (Synergie HT, Bio-Tek, USA), being related with the quantity of formazan product and directly proportional to the number of living cells in the constructs. Three samples of each nanofiber mesh per time point were characterized.

Cell proliferation was quantified by the total amount of double-stranded DNA, along the culturing time. Quantification was performed using the Quant-iT ${ }^{\mathrm{TM}}$ PicoGreen dsDNA Assay Kit (Invitrogen ${ }^{\mathrm{TM}}$, Molecular Probes ${ }^{\mathrm{TM}}$, Oregon, USA), according to the instructions of the manufacturer. Briefly, cells in the construct were lysed by osmotic and thermal shock and the supernatant used for the DNA quantification assay. The fluorescence of the dye was measured at an excitation wavelength of 485 $20 \mathrm{~nm}$ and at an emission wavelength of 528/20 nm, in a microplate reader (Synergie HT, Bio-Tek, USA). Triplicates were made for each sample and per culturing time. The DNA concentration for each sample was calculated using a standard curve (DNA concentration ranging from 0.0 to $1.5 \mu \mathrm{g} / \mathrm{mL}$ ) relating quantity of DNA and fluorescence intensity.

\subsection{Alkaline phosphatase quantification}

The concentration of alkaline phosphatase (ALP) was determined for all time culture periods, using the lysates used for DNA quantification. Briefly, the ALP quantity was assessed using the $p$-nitrophenol assay, in which the colourless nitrophenyl phosphate disodium salt (pnPP; Sigma, USA) is hydrolysed by the ALP (Sigma, USA) at pH 10.5 and temperature of $37^{\circ} \mathrm{C}$ to form yellow free $p$-nitrophenol. The reaction was stopped by addition of $2 \mathrm{~m} \mathrm{NaOH}$ (Panreac Quimica, Spain) and the absorbance read at $405 \mathrm{~nm}$ in a microplate reader (Bio-Tek, Synergie HT, USA). Standards were prepared with $10 \mu \mathrm{mol} / \mathrm{mL} p$-nitrophenol (pNP; Sigma, USA) solution, to obtain a standard curve ranging from 0 to $0.250 \mu \mathrm{mol} / \mathrm{mL}$. Triplicates of each sample and standard were made, and the ALP concentrations read off from the standard curve.

\subsection{Alizarin red staining}

After culture, the DEX-loaded nanofiber meshes-hBMSCs constructs were fixed in $10 \%$ formalin solution neutral buffer (Sigma-Aldrich, Germany) for 30 min and maintained in phosphate buffer saline (PBS) until further use. The constructs were further stained with a $2 \%$ Alizarin Red solution (Merk, Germany) in distilled water for $5 \mathrm{~min}$, and finally washed with distilled water. Stained constructs were observed under an optical microscope (BX61, Olympus Corporation, Germany) and images captured by a digital camera (DP70, Olympus Corporation, Germany).

\subsection{Immunodetection of bone-specific proteins}

Immunocytochemistry was performed following the streptavidin-biotin-peroxidase complex approach (R.T.U. Vectastain ${ }^{\circledR}$ Universal Elite ${ }^{\circledR}$ ABC kit; Vector Laboratories Inc., Burlingame, CA), using a rabbit polyclonal antibody against osteopontin (Abcam Ltd., Cambridge, UK; dilution 1:1500), a mouse monoclonal antibody against osteocalcin (clone OC4-30, Abcam Ltd., Cambridge, UK; dilution 1:100) and a rabbit polyclonal antibody against bone sialoprotein II (Chemicon ${ }^{\circledR}$ International Inc., Germany; dilution 1:2500). Prior to the immunocytochemistry procedure, constructs were fixed in $10 \%$ formalin solution neutral buffer (Sigma-Aldrich, Germany) for $30 \mathrm{~min}$ and maintained in phosphate buffer saline (PBS) until further use. The constructs were treated with $0.3 \%$ hydrogen peroxide in methanol during $30 \mathrm{~min}$ to inactivate the endogenous peroxidases. After washing with PBS, the constructs were blocked with $2.5 \%$ normal horse serum for 20 min at room temperature to avoid unspecific reactions. Primary antibodies were incubated overnight at $4{ }^{\circ} \mathrm{C}$. Negative controls were set in the absence of primary antibodies incubation. After washing in PBS, the samples were incubated for 30 min with biotinylated secondary antibody anti-rabbit/mouse IgG, followed by incubation with streptavidin-peroxidase complex (Elite $A B C$ Reagent). The immune reaction was visualized using $D A B$ as a chromogen (DAB Substrate Reagent from Peroxidase Substract Kit; Vector Laboratories Inc, Burlingame, CA). The constructs were observed under an optical microscope (BX61, Olympus Corporation, Germany) and images captured by a digital camera (DP70, Olympus Corporation, Germany).

\subsection{RNA isolation and real-time quantitative polymerase chain reaction ( $q P C R$ )}

Total RNA from the constructs was extracted using the Trizol ${ }^{\circledR}$ (Invitrogen, Life Technologies Inc., UK) method according to the manufacturer's directions. Briefly, at each culturing time the constructs were washed with PBS, immersed in Trizol and storage at $-80{ }^{\circ} \mathrm{C}$ until further use. Proteins were removed with chloroform extraction, and the RNA pellets were washed once with isopropyl alcohol and once with $70 \%$ ethanol. The total RNA pellets were reconstituted in Rnase free water (Gibco, Invitrogen, UK).

Reverse transcriptase (RT)-PCR was performed according to the protocol from iScript $^{\mathrm{TM}}$ cDNA synthesis kit (BioRad, Hercules, CA, USA). Briefly, a reaction mixture consisting of $1 \times$ iScript Reaction Mix, $1 \mu \mathrm{L}$ iScript Reverse Transcriptase, RNA template (300 ng total RNA) and nuclease-free water was prepared, in $20 \mu \mathrm{L}$ of total volume. The single-strand cDNA synthesis occurred by incubating the complete reaction mixture $5 \mathrm{~min}$ at $25^{\circ} \mathrm{C}$, followed by $30 \mathrm{~min}$ at $42{ }^{\circ} \mathrm{C}$ and terminated by an incubation at $85^{\circ} \mathrm{C}$ for $5 \mathrm{~min}$.

Amplification of the target cDNA for real-time PCR quantification was performed according to manufacturer, using $2 \mu \mathrm{L}$ RT cDNA products, $1 \mu \mathrm{m}$ each primer (bonespecific primer sets listed in Table 1), $1 \times$ iQ SYBR Green Supermix (BioRad, Hercules, CA, USA) and nuclease-free water, in a final volume of $25 \mu \mathrm{L}$. Forty-four cycles of denaturation $\left(95^{\circ} \mathrm{C}, 10 \mathrm{~s}\right)$, annealing (temperature dependent on the gene, $30 \mathrm{~s}$ ) and extension $\left(72{ }^{\circ} \mathrm{C}, 30 \mathrm{~s}\right)$ were carried out in the gradient thermocycler MiniOpticon real-time PCR detection system (BioRad, Hercules, CA, USA) for all genes. The transcripts expression data were normalized to the housekeeping gene glyceraldehydes-3-phosphate-dehygrogenase $(G A P D H)$ and the relative quantification calculated by the $\Delta \mathrm{CT}$ method.

\subsection{Statistical analysis}

Statistical analysis was performed using the SPSS statistic software (Release 15.0.0 for Windows). Firstly, a Shapiro-Wilk test was used to ascertain about the data normality. The results indicated that nonparametric tests should be used for all comparisons. A Kruskal-Wallis test followed by Turkey's HSD test were performed to analyze the effect of the DEX-loaded electrospun nanofibrous meshes on the hBMSCs' viability and proliferation, ALP quantification, and osteogenic genotype. $P$ values lower than 0.01 were considered statistically significant.

\section{Results}

\subsection{Physicochemical properties of the dexamethasone-loaded electrospun PCL nanofiber meshes}

In the present work, a glucocorticoid drug - dexamethasone was dissolved at different concentrations $(5,10,15$ and 20 wt.\% polymer) in the polymeric solution to be electrospun. A mesh-like structure composed by randomly distributed fibers with diameters ranging from $150 \mathrm{~nm}-1.6 \mu \mathrm{m}$ (Fig. $1 \mathrm{~B}-\mathrm{E}$ ) was produced. The incorporation of dexamethasone at concentrations ranging from 5 to $15 \mathrm{wt} . \%$ (Fig. 1B-D) shows the appearance of thinner fibers in larger number than in the control nanofiber meshes (Fig. 1A). However, those differences in morphology are probably insufficient to induce any specific cell response. This observation was expected since the solvent is able to dissolve simultaneous the polymer and the incorporated drug. In this way, the drug is very well dispersed in the bulk polymeric matrix of the electrospun nanofibers without inducing significant morphological variation of the electrospun fibers. Relevant morphological alteration, namely an increment of nanofibers diameter, was observed only in the electrospun meshes with an incorporation of 20 wt.\% DEX (Fig. 1E).

To confirm the presence of dexamethasone incorporated in the electrospun PCL nanofibers an FTIR analysis was performed. Fig. 2 shows the spectra of PCL nanofibers, raw dexamethasone and also of the different DEX-loaded electrospun PCL nanofiber meshes. The characteristic peaks of dexamethasone at 900 and $1650 \mathrm{~cm}^{-1}$ are observed in the nanofiber meshes prepared with the different

Table 1

Primers list of osteogenic markers.

\begin{tabular}{|c|c|c|c|}
\hline Gene & & Primer sequences $\left(5^{\prime}-3^{\prime}\right)$ & $T_{\mathrm{m}}\left({ }^{\circ} \mathrm{C}\right)$ \\
\hline \multirow[t]{2}{*}{ ALP } & Sense & CTCCTCGGAAGACACTCTG & 60.0 \\
\hline & Antisense & AGACTGCGCCTGGTAGTTG & \\
\hline \multirow[t]{2}{*}{$\mathrm{OP}$} & Sense & GGGGACAACTGGAGTGAAAA & 58.4 \\
\hline & Antisense & CCCACAGACCCTTCCAAGTA & \\
\hline \multirow[t]{2}{*}{ BSP } & Sense & CAACAGCACAGAGGCAGAAAAC & 59.9 \\
\hline & Antisense & CCTCGTATTCAACGGTGGTG & \\
\hline \multirow[t]{2}{*}{$\mathrm{OC}$} & Sense & CTGAGAGGAGCAGAACTGG & 61.4 \\
\hline & Antisense & GGCAGCGAGGTAGTGAAGAG & \\
\hline \multirow[t]{2}{*}{ Runx2 } & Sense & TTCCAGACCAGCAGCACTC & 58.1 \\
\hline & Antisense & CAGCGTCAACACCATCATTC & \\
\hline \multirow[t]{2}{*}{ Osterix } & Sense & CCCTTTACAAGCACTAATGG & 57.1 \\
\hline & Antisense & ACACTGGGCAGACAGTCAG & \\
\hline \multirow[t]{2}{*}{ GAPDH } & Sense & ACAGTCAGCCGCATCTTCTT & 58.4 \\
\hline & Antisense & GACAAGCTTCCCGTTCTCAG & \\
\hline
\end{tabular}



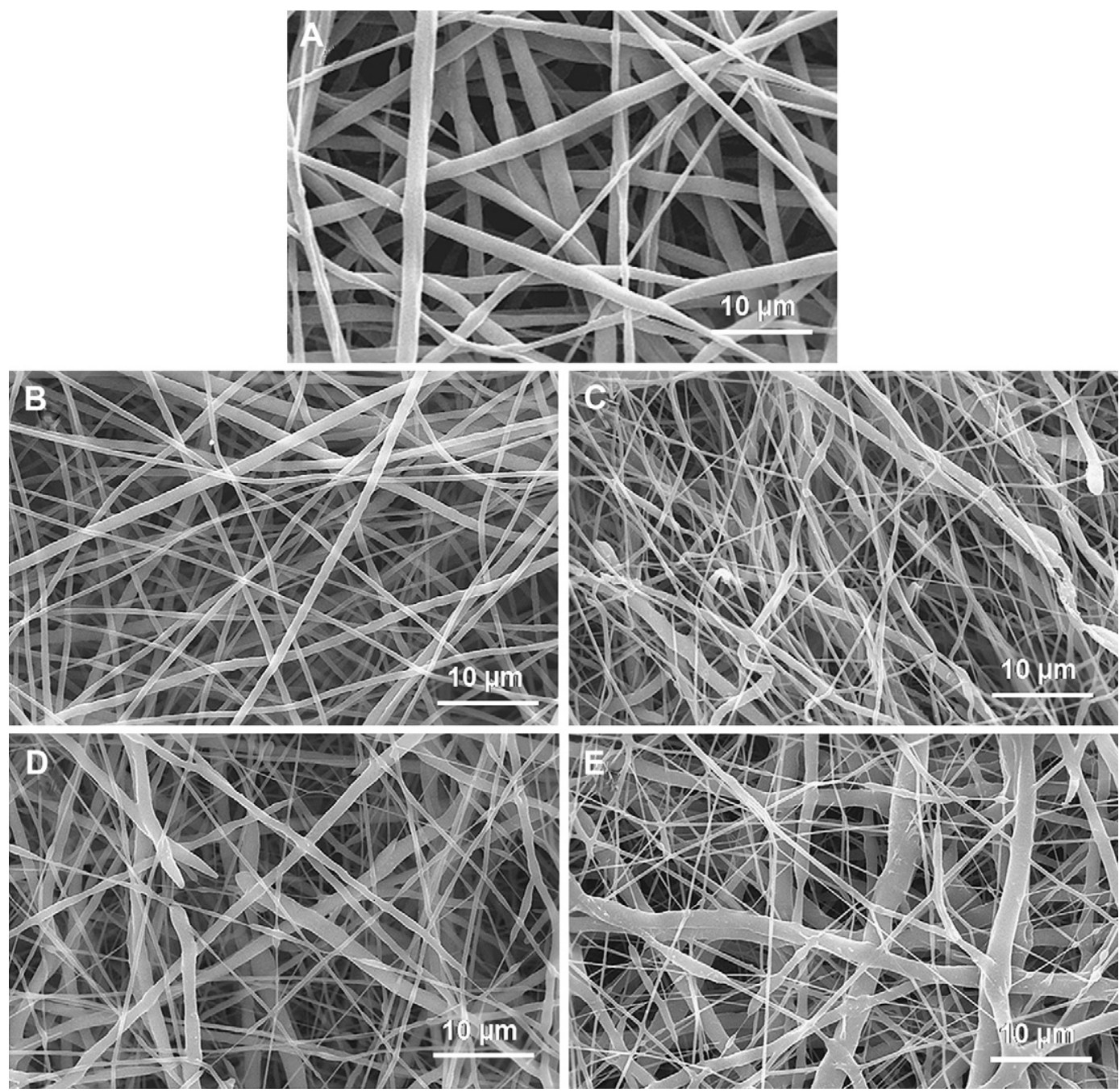

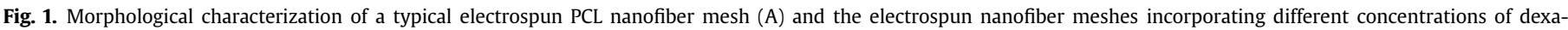
methasone: 5 wt.\% (B), 10 wt.\% (C), 15 wt.\% (D) and 20 wt.\% (E).

DEX concentrations, which confirms the presence of the glucocorticoid in the polymeric matrix.

Thermal analysis of the DEX-loaded nanofiber meshes was carried out to ascertain about the crystalline state of the incorporated dexamethasone. Fig. 3A shows the DSC thermograms of
PCL nanofiber meshes and raw dexamethasone. In this graph is possible to observe the melting peaks of the polymer at $56.9{ }^{\circ} \mathrm{C}$ and of dexamethasone at $262.2^{\circ} \mathrm{C}$. However, the characteristic endothermic peak of dexamethasone is not present in the DEXloaded nanofiber meshes (Fig. 3B). These thermal properties of

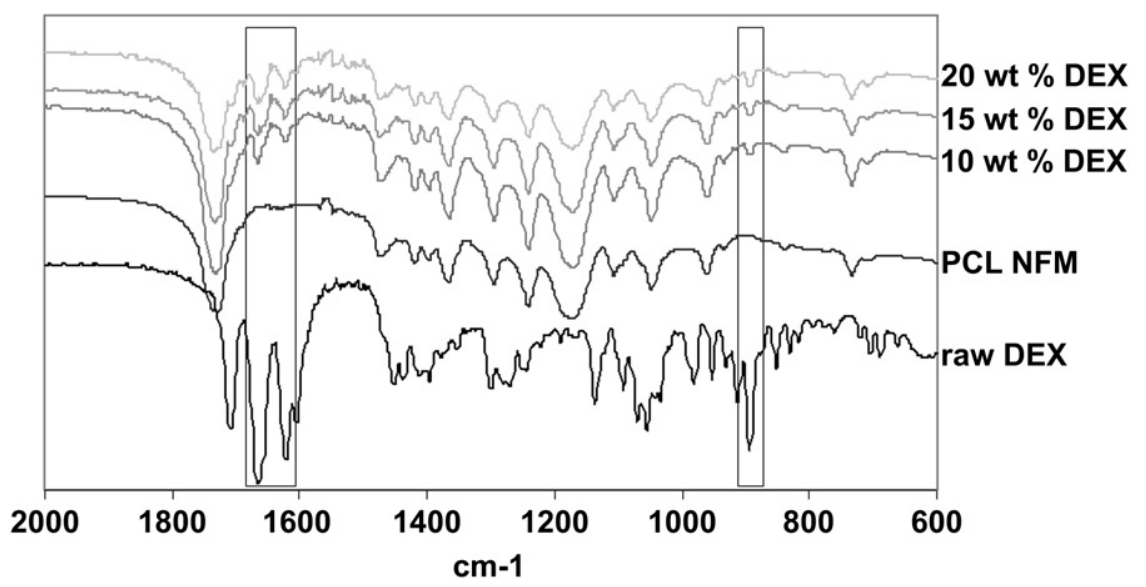

Fig. 2. FTIR spectra of raw dexamethasone, control PCL NFMs, DEX-loaded PCL NFMs at 10 wt.\%, 15 wt.\% and 20 wt.\%. 

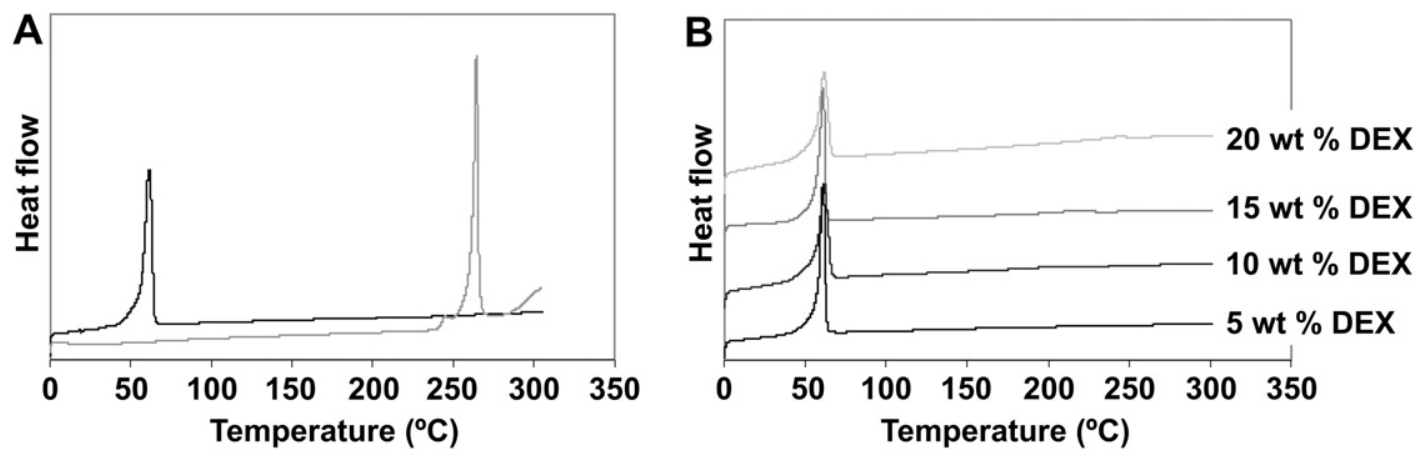

Fig. 3. DSC thermogram of control PCL NFMs (black line) and raw dexamethasone (grey line) (A), and DEX-loaded PCL nanofibers at 5 wt.\%, 10 wt.\%, 15 wt.\% and 20 wt.\% (B).

DEX-loaded PCL nanofiber meshes suggest that dexamethasone, precipitated from the polymeric/organic solution during the electrospinning processing, is not in its crystalline state when incorporated in the nanofiber meshes. This is a typical observation, since the mobility of the DEX inside the fibers is highly hindered.
3.2. Release kinetics of dexamethasone from the electrospun PCL nanofiber meshes

The release profile of dexamethasone from the different DEXloaded PCL NFMs was followed during 21 days, in accordance with the culture time usually needed to observe a complete osteogenic

A

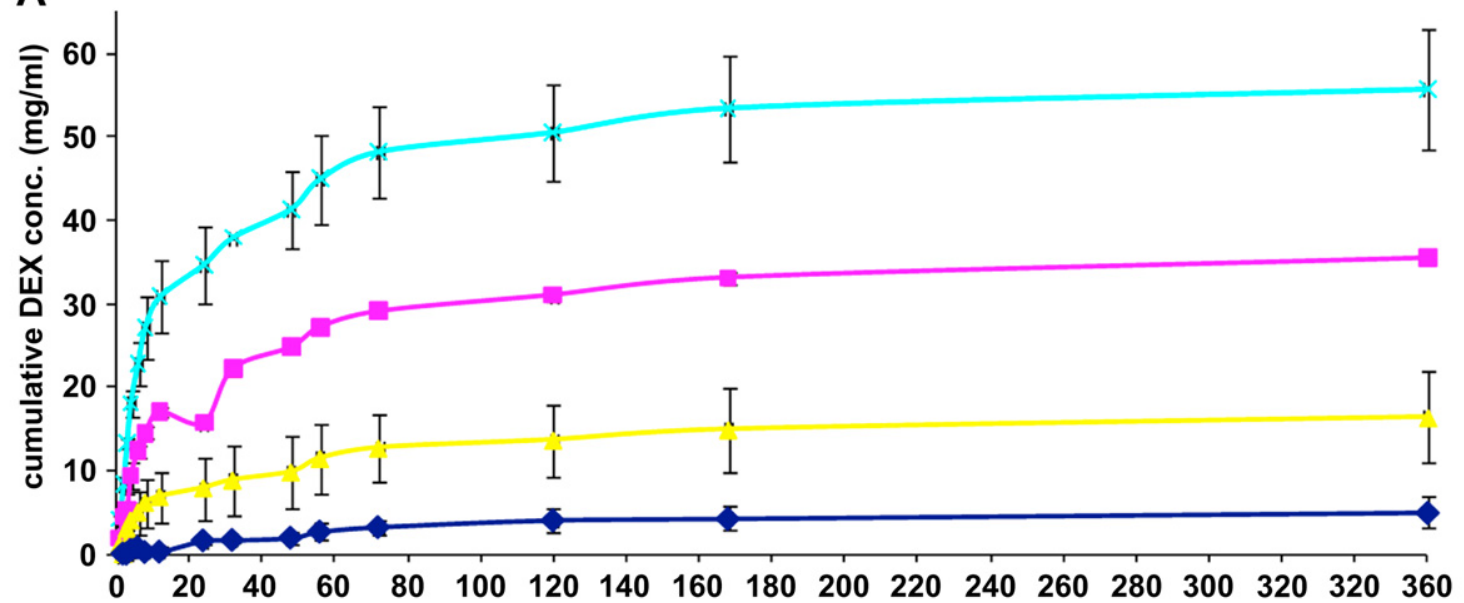

B

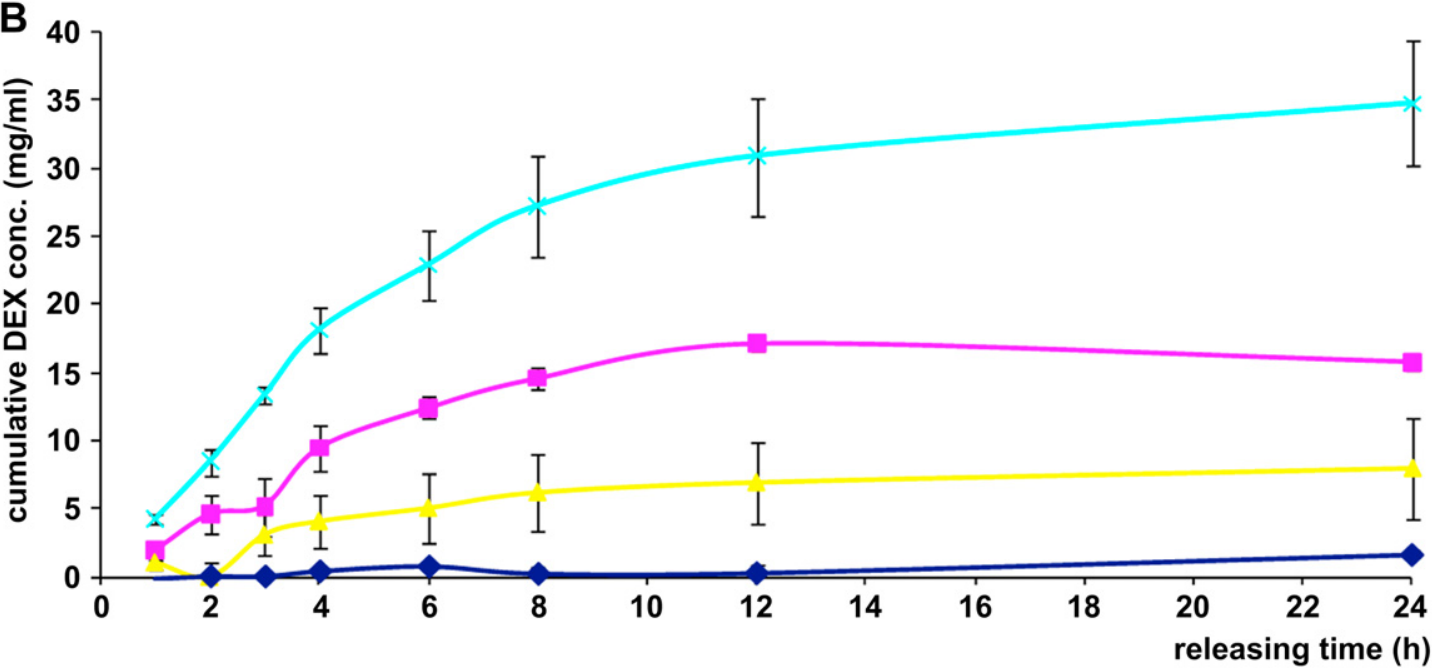

Fig. 4. Release profile of the different dexamethasone concentrations incorporated into the electrospun PCL nanofiber meshes. 
differentiation of MSCs in vitro. As depicted in Fig. 4, a significant initial release of dexamethasone - burst release - was observed in the case of PCL NFMs incorporating above $5 \mathrm{wt}$.\% of the growth/ differentiation factor. It was noticed that a higher amount of drug lead to a faster release rate. After $100 \mathrm{~h}$, a slow sustained release of dexamethasone was observed for all systems. Considering the release profiles of the different DEX-loaded PCL NFMs and the dexamethasone concentrations achieved, the 15 wt.\% DEX-loaded PCL NFMs was chosen for further in vitro biological assays.

\subsection{Biological activity of the dexamethasone released from the electrospun nanofiber meshes}

To ascertain about the biological activity, and inherent structural integrity, of the released dexamethasone from the electrospun PCL NFMs, human bone marrow mesenchymal stem cells (hBMSCs) were cultured on 15 wt.\% DEX-loaded PCL NFMs. From the MTS assay data (Fig. 5) it was possible to observe that, until the 14th day of culture, the different culture conditions did not induce significant changes over hBMSCs viability $(p>0.01)$. However, at day 21, hBMSCs cultured on DEX-loaded NFMs on dexamethasone-absente osteogenic differentiation medium (NFM+DEX_Osteo), on DEXloaded NFMs (NFM+DEX_Basal) and on control PCL NFMs (NFM_Basal) on basal medium showed significant lower viability than those cultured on standard osteogenic differentiation medium (NFM_Osteo) $(p<0.01)$. Moreover, for this culturing time, DEXloaded NFMs cultured on basal (NFM+DEX_Basal) and dexamethasone-absent osteogenic differentiation media (NFM+DEX_Osteo) presented significantly higher hBMSCs' viability than those cultured on control PCL NFMs under basal conditions (NFM_Basal) $(p<0.01)$. Complementary to the analysis of hBMSCs' viability along the course of the experiment, the proliferation or replication rate of those cells was also quantified based on the DNA content (Fig. 6). DEX-loaded NFMs constructs cultured on dexamethasone-absent osteogenic differentiation medium (NFM+DEX_Osteo) present significant lower proliferation capability than hBMSCs cultured under all the other

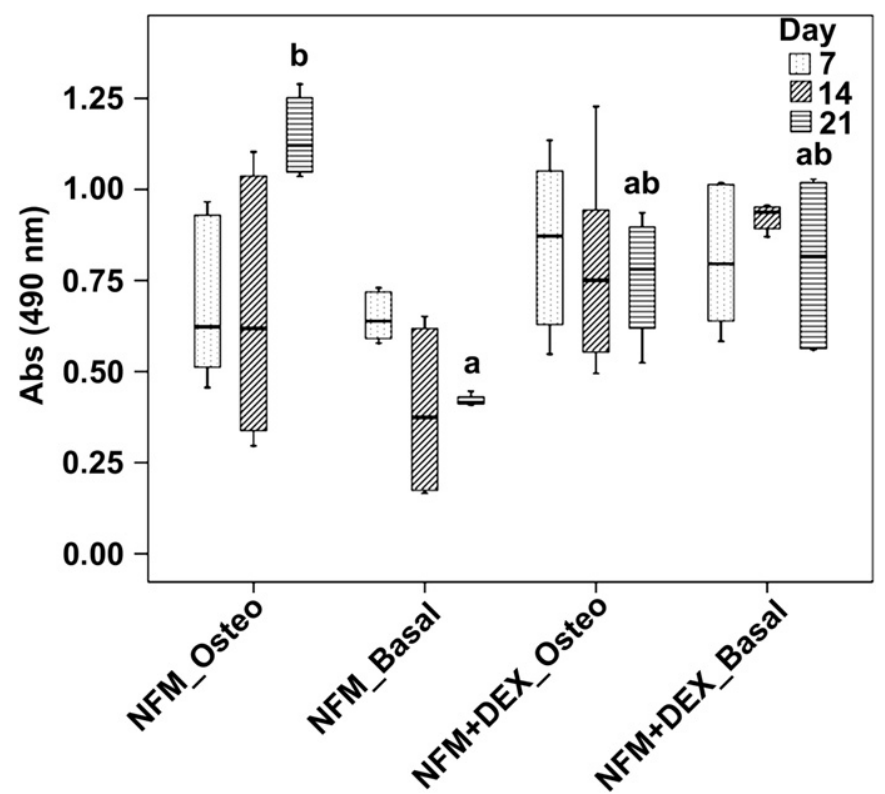

Fig. 5. Box plot of the hBMSCs viability (MTS assay) cultured on NFM_Osteo, NFM_Basal, NFM+DEX_Osteo and NFM+DEX_Basal, after 7, 14 and 21 days. Data were analyzed by nonparametric way of a Kruskal-Wallis test followed by Tukey's HSD test: $\mathrm{a}$, denotes significant differences compared to NFM_Osteo; b, denotes significant differences compared to NFM_Basal.

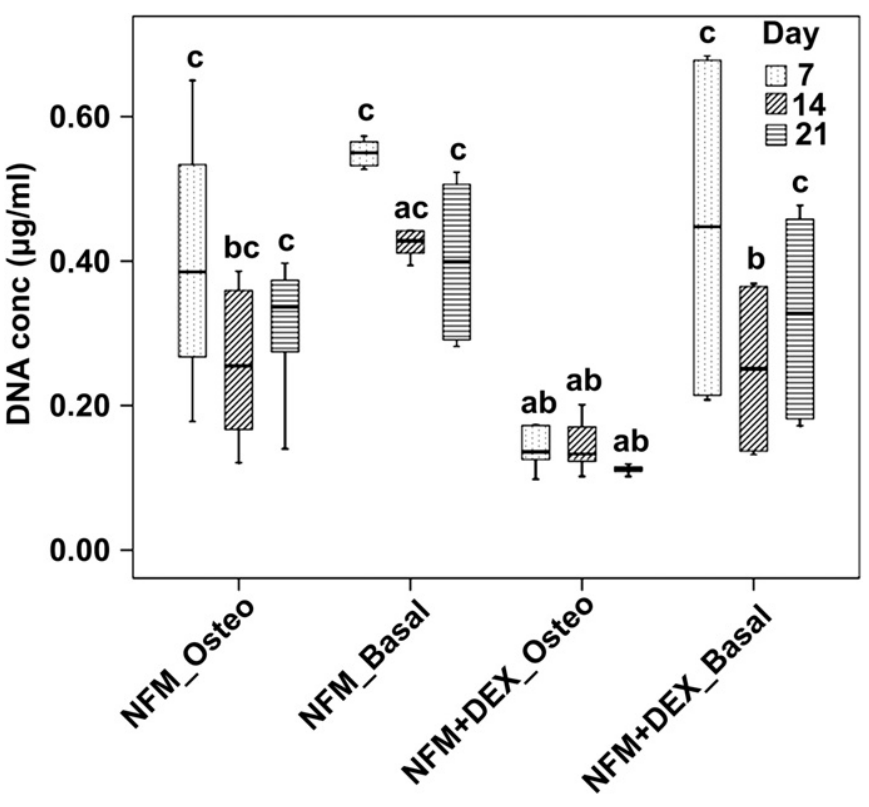

Fig. 6. Box plot of the hBMSCs proliferation (DNA concentration) cultured on NFM_Osteo, NFM_Basal,NFM+DEX_Osteo and NFM+DEX_Basal, after 7, 14 and 21 days. Data were analyzed by nonparametric way of a Kruskal-Wallis test followed by Tukey's HSD test: a denotes significant differences compared to NFM_Osteo; b denotes significant differences compared to NFM_Basal; c denotes significant differences compared to NFM+DEX_Osteo.

conditions ( $p<0.01)$. Conversely, control PCL NFMs cultured under basal medium (NFM_Basal) demonstrated significantly higher DNA concentration than all the other substrates and corresponding culture medium $(p<0.01)$, just for the 14 th day.

Despite the above described proliferative cell population cultured on the DEX-loaded PCL NFMs under basal (NFM+DEX_Basal) or dexamethasone-absent osteogenic differentiation media

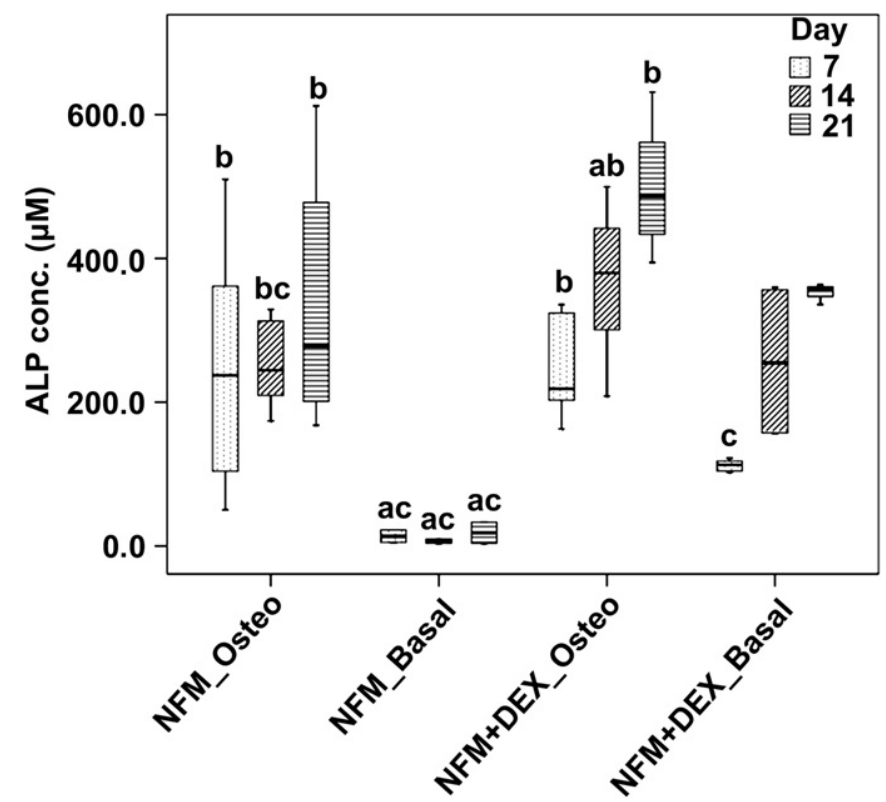

Fig. 7. Box plot of the alkaline phosphatase (ALP) concentration produced by hBMSCs cultured on NFM_Osteo, NFM_Basal, NFM+DEX_Osteo and NFM+DEX_Basal, after 7, 14 and 21 days. Data were analyzed by nonparametric way of a Kruskal-Wallis test followed by Tukey's HSD test: a, denotes significant differences compared to NFM_Osteo; b, denotes significant differences compared to NFM_Basal; c, denotes significant differences compared to NFM+DEX_Osteo. 
(NFM+DEX_Osteo), the expression of alkaline phosphatase (ALP) is similar to the one observed in control PCL NFMs cultured on standard osteogenic differentiation medium (NFM_Osteo) $(p>0.01)$ (Fig. 7). An exception was observed for the 14 days of culture: hBMSCs cultured on DEX-loaded NFMs under dexamethasone-absent conditions (NFM+DEX_Osteo) produced significant higher quantities of ALP than the control PCL NFMs under osteogenic conditions (NFM_Osteo) $(p<0.01)$. Undifferentiated hBMSCs cultured on the control PCL NFMs (NFM_Basal) produce negligible quantities of ALP, as depicted by the significantly lower ALP concentration compared to all the other substrates and corresponding culture medium $(p<0.01)$. Consequently, further characterization of the osteogenic phenotype and genotype herein reported does not include this condition.

The morphology and distribution of the hBMSCs cultured on DEX-loaded NFM was analyzed by SEM. The cells interacted with the fibrous structure, bridging contiguous fibers and formed a dense cellular construct that was clearly visible at day 7 (Fig. 8A). It was also possible to observe deposition of minerals over the dense cellular layer from day 14 onward (Fig. 8B and C), resulting from the matrix mineralization that occurs along the differentiation of hBMSCs into osteoblasts. To confirm the matrix mineralization, an alizarin red staining was performed to specifically detect the calcium present in those mineralized nodules. The intense red/ purple dots dispersed in the construct correspond to the mineralized nodules, after 14 and 21 days of hBMSCs culture on DEXloaded NFM under dexamethasone-absent osteogenic differentiation medium formulation (Fig. 8D and E). Using Energy Dispersive
Spectrometry (EDS) it was possible to identify the elemental composition of the minerals deposited on the DEX-loaded PCL NFM-hBMSCs constructs (Fig. 8F). EDS data confirms the presence of Calcium and Phosphorous deposition by the adjacent cells, and the increasing amount from day 14-21 of hBMSCs culture under dexamethasone-absent osteogenic differentiation medium formulation. Those observations were not found in control PCL NFM cultured with hBMSCs under standard osteogenic differentiation conditions, nor in the DEX-loaded PCL NFM culture with hBMSCs on basal medium (data not included here).

The osteogenic phenotype of hBMSCs seeded onto DEX-loaded nanofiber meshes was also assessed by the immunodetection of some specific osteoblastic proteins, namely osteopontin, bone sialoprotein and osteocalcin. Photomicrographs indicate a progressive expression of the specific osteoblastic glycoprotein osteopontin on the DEX-loaded NFMs-hBMSCs constructs during the 21 days of culture (Fig. 9). In the cases of bone siaoloprotein and osteocalcin protein, the maximum expression seems to be achieved at the 14th day of hBMSCs culture under dexamethasone-absent osteogenic differentiation medium. Similar osteoblastic protein expression pattern was observed in the control PCL NFM cultured with hBMSCs under standard osteogenic differentiation conditions and, also, in the DEX-loaded PCL NFM culture with hBMSCs in basal medium (data not shown).

Complementary to the phenotypic analysis, a genotypic quantification of the expression of some bone-specific genes was performed to ascertain about the differentiation level of the seeded hBMSCs on DEX-loaded PCL NFMs. The relative expression of those
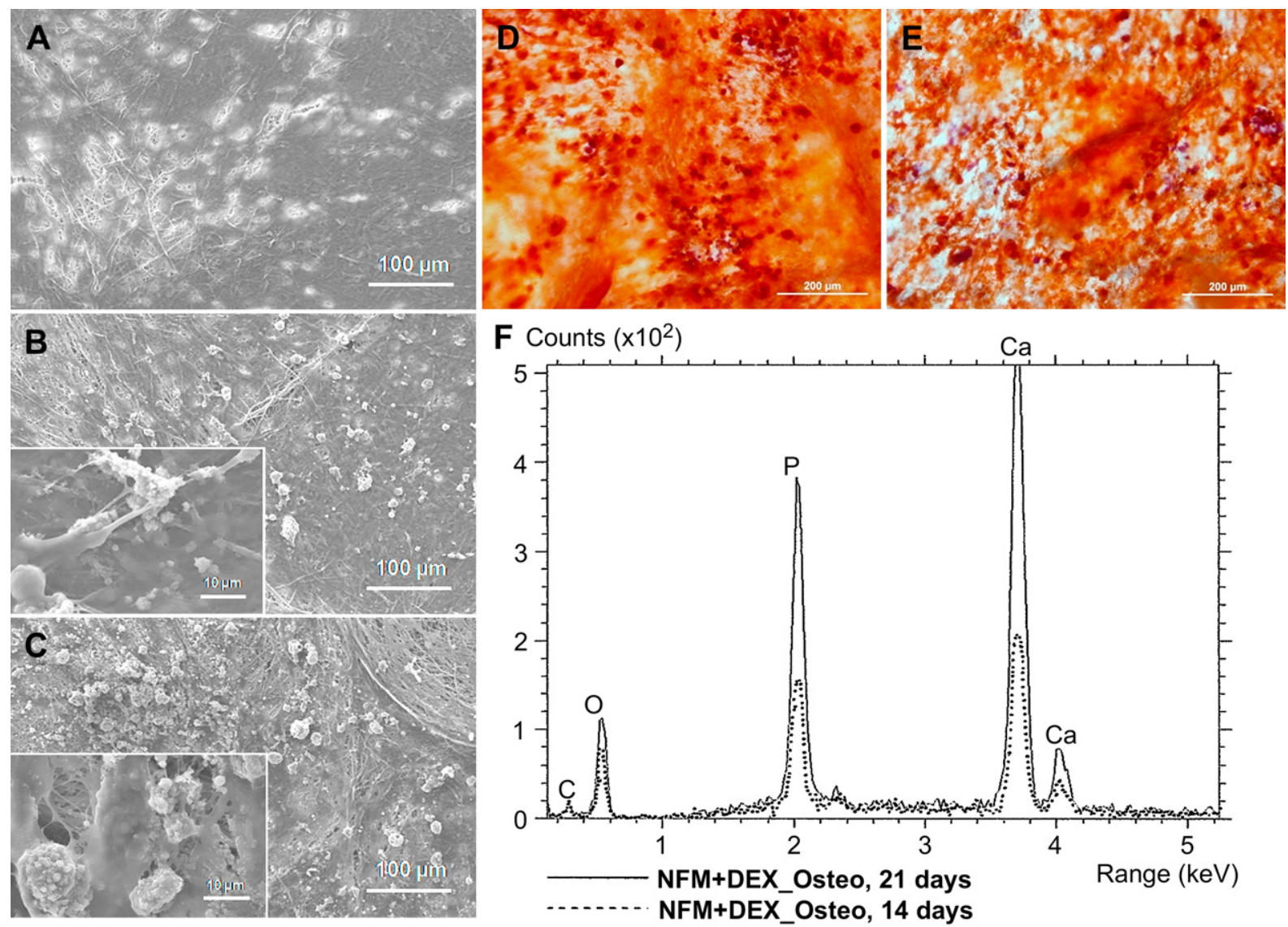

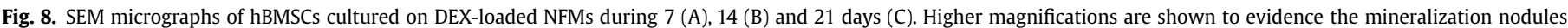

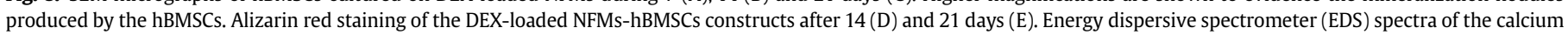
phosphates nodules produced by hBMSCs cultured on DEX-loaded NFMs after 14 and 21 days (F). 


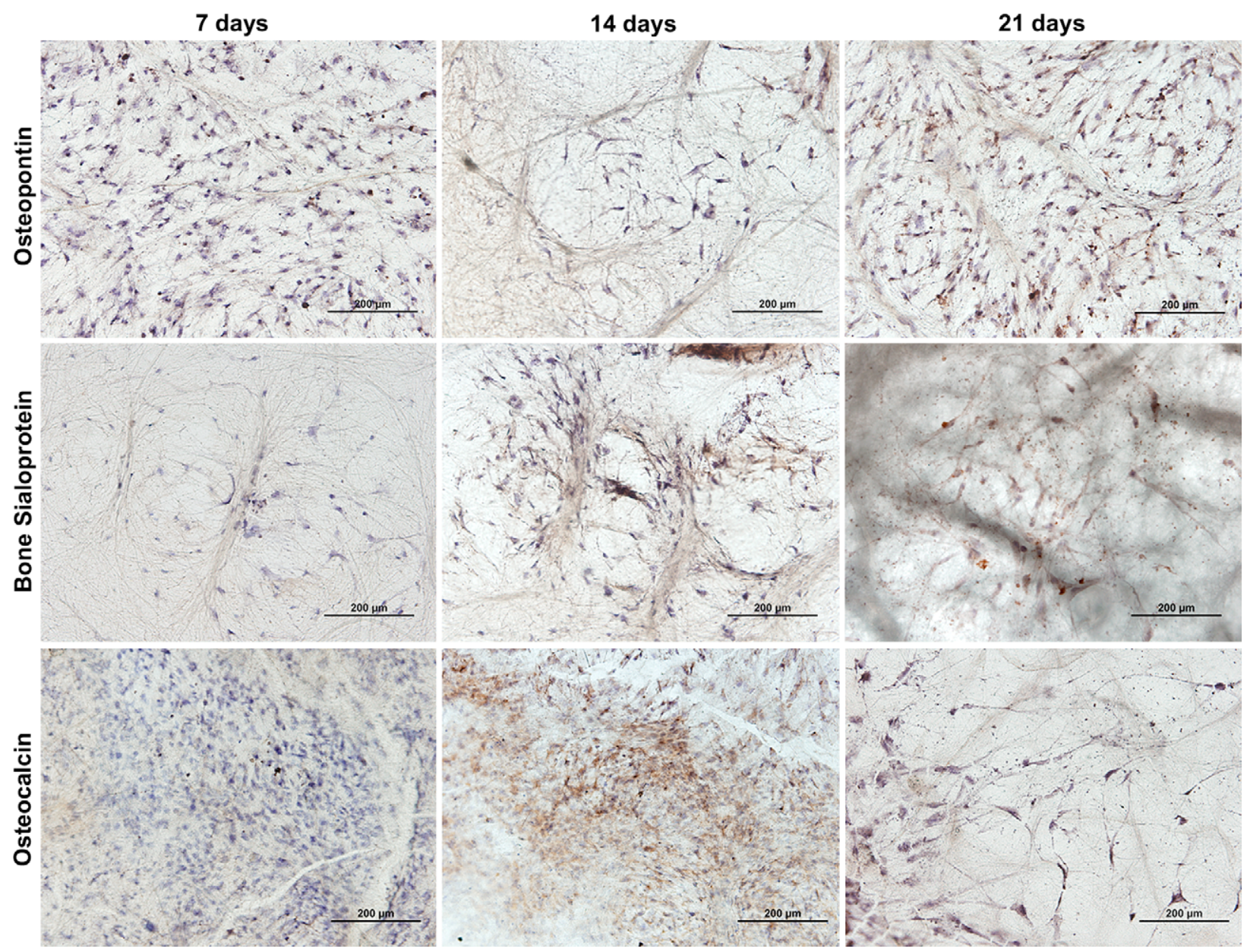

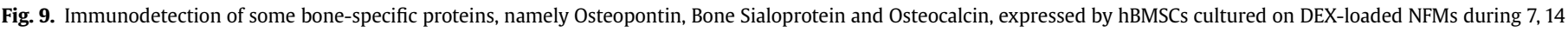
and 21 days.

genes was normalized against the housekeeping gene GAPDH and compared to hBMSCs cultured on control PCL NFM under standard osteogenic differentiation conditions. A constitutive expression of all mRNA transcripts (i.e. Alkaline Phosphatase, Osteopontin, Bone Sialoprotein, Osteocalcin, Runx-2 and Osterix) was observed during the 21 days of culture. Although Alkaline Phosphatase was present in a stable fashion, its expression is significantly lower in hBMSCs cultured on DEX-loaded PCL NFMs, in both culture conditions $(p<0.01)$ (Fig. 10). Among those bone-specific genes, Bone Sialoprotein and Osterix were the highest expressed, followed by the Osteopontin gene.

\section{Discussion}

\subsection{Electrospun nanofiber meshes incorporating and releasing dexamethasone}

The rate of drug release depends on a multitude of factors, such as the nature of the polymer matrix (i.e. chemical composition, backbone stability and water solubility), matrix architecture, loading capacity and drug-matrix interaction. Therefore, for the development of an ideal drug release system, the polymer should be biodegradable, have appropriate degradation rate, nontoxic degradation products, appropriate solubility and simplicity of fabrication [30]. The herein developed drug carrier was based on the convenient processing of nanofibrous structures by electrospinning, using an adequate organic solvent to simultaneously dissolve the biodegradable polymer - polycaprolactone and the incorporated drug - dexamethasone. This drug release system allows a suitable interaction between PCL and dexamethasone, being the drug well distributed in the polymer matrix. Consequently, the drug presents a good physicochemical interaction with the polymer. The structural integrity of the differentiation factor, as well as its biological activity could be maintained during the processing step. The large surface area associated with the nanofiber mesh allows fast and efficient solvent evaporation, which limits the period of time of the incorporated drug to recrystallize, favouring the maintenance of amorphous dispersed phase $[2,6,13]$. The presence of amorphous dexamethasone in our polymeric carrier was also observed in our DSC data.

The most widely investigated release system for the encapsulation of bioactive compounds is micro- and nanoparticles. Nanoparticles have facility to diffuse through cell membranes, allowing controlling or modifying the cell activity. The osteogenic differentiation factor herein incorporated in electrospun biodegradable nanofibers was already studied by our group and others in different drug release systems, including micro- and nanoparticles and scaffolds [31-39]. Those polymeric drug release systems are based in starch-polycaprolactone (SPCL) microparticles or carboxymethylchitosan/poly(amidoamine) dendrimer (CMCht/PAMAM) nanoparticles. Both devices were intended to be used as part of an injectable system or in a polymeric 3D scaffold. In the present work 
it was presented a dexamethasone release system, based on electrospun biodegradable nanofibers as carrier. It is aimed at developing a system that simultaneously acts as a scaffold for mesenchymal stem cells differentiation toward the osteogenic lineage. The next generation of engineered tissues relies on the development of biodegradable scaffolds as physical supports to release bioactive molecules that control cell attachment, proliferation and differentiation [40].

Due to the relatively slow wetting, as a consequence of the highly hydrophobic character of the PCL NFM and its slow degradation rate, it was possible to deduce that dexamethasone release occurred primarily by diffusion, demonstrating that a biodegradable nanofibrous system can be used to obtain a release profile that was effective in differentiating stem cells. The burst release effect common in polymer-based release systems, is connected to the high gradients of concentration observed at the initial stages of release. In the system of 20 wt.\% DEX-loaded PCL NFMs, the burst release effect may be primarily caused by an imperfect distribution/entrapment of the dexamethasone into the polymer matrix or by their tendency to migrate to the nanofiber surface during the electrospinning process [41]. As the nanofibers are placed in an aqueous environment, at the initial stage water penetrates into the nanofibers surface and a large amount of dexamethasone is faster released due to the initial surface erosion. Subsequently, water permeates into the bulk of the nanofibers causing polymer swelling, bond cleavage and bulk erosion, generating interconnecting pores and channels within nanofibers that allow the slow sustained release of the remaining dexamethasone [41].

\subsection{Bioactivity of the dexamethasone loaded in the electrospun nanofiber meshes}

Drug release systems are developed to maximize the therapeutic activity while minimizing the toxic side effects of drugs. However, the scope of those devices is limited for targeting tissues rather than individual cells [1]. In tissue engineering, the required bioactive molecules are typically supplied to the cells growing on the scaffold in the culture medium, in the soluble form. The present drug carrier was designed to operate as a synthetic extracellular matrix - scaffold - for mesenchymal stem cell growth and, simultaneously, to allow a direct supply of the differentiation factor to the adherent cells. It is intended to supply locally the required amount needed to promote the proliferation and differentiation towards the osteogenic lineage. To validate this hypothesis, an osteogenic differentiation study was conducted. The osteogenic differentiation is sensitive to the dose and duration of exposure to the glucocorticoid [42]. Jaiswal et al. suggested that the effective concentration of DEX for the osteogenic differentiation of MSCs should be in the range of $10-100 \mathrm{~nm}$, showing toxic effects at 1000 пм [24].

The electrospun PCL NFMs loaded with 15 wt.\% dexamethasone were cultured with hBMSCs under dexamethasone-absent
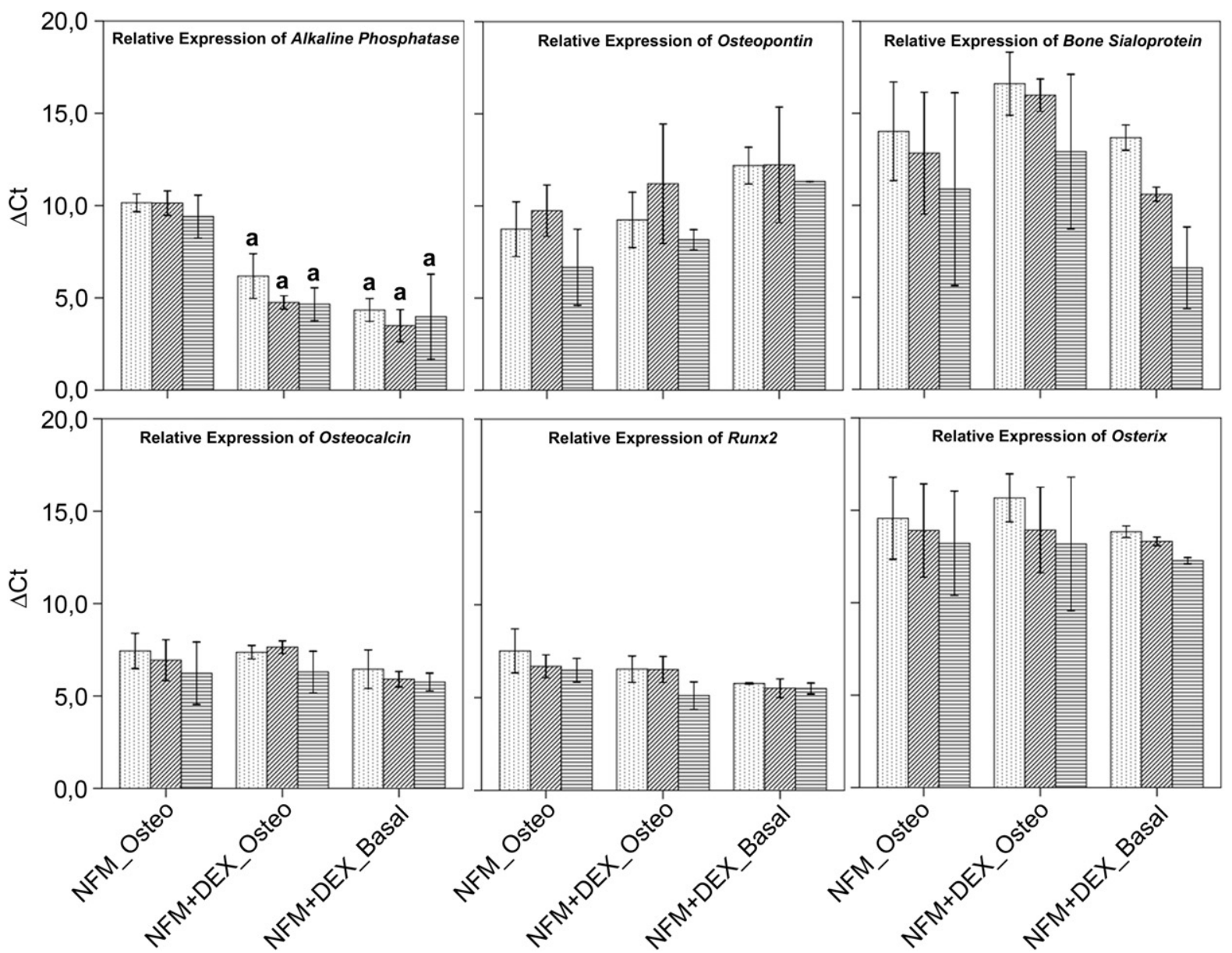

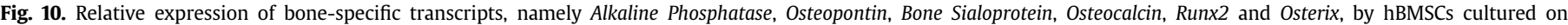

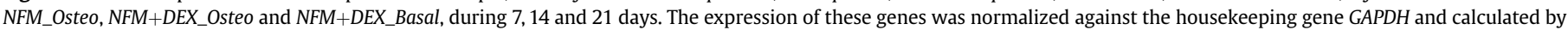
the $\triangle C T$ method. Data were analyzed by nonparametric way of a Kruskal-Wallis test followed by Tukey's HSD test: a, denotes significant differences compared to NFM_Osteo. 
osteogenic differentiation medium formulation. Our biological results confirm the biological activity of the incorporated dexamethasone, as shown by the increased amount of deposited calcium phosphates produced by the differentiated cells (also stained by alizarin red and identified by EDS). Additionally, the increasing concentration of the enzyme alkaline phosphatase (ALP) also confirms the osteoblastic differentiation and mineralization of hBMSCs cultured on DEX-loaded PCL NFMs. In fact, this enzyme catalyses the splicing of phosphate from nonphosphoric esters, constituting a biochemical indicator of the presence of osteoblasts and the deposition of mineralized ECM, since MSCs produce negligible amounts of this enzyme, as depicted by our results. This hypothesis of osteoblastic differentiation was confirmed by the expression of specific osteoblastic glycoproteins, namely osteopontin and bone sialoprotein, which are also present in the ECM of bone. The deposition and mineralization of ECM, previously observed in the SEM micrographs, stained with alizarin red and chemically identified by EDS, were also confirmed by the immunodetection of the osteocalcin protein, which binds strongly to apatite and calcium.

In the literature three periods were identified on the osteogenic differentiation of embryonic stem cells (ES) [43], corresponding to the expression pattern of the osteoblastic markers: a proliferative phase, which is followed by the period of matrix deposition, and lastly the mineralization phase. The highest expression peak of Osteopontin mRNA at 14 days of hBMSCs culture determines the end of the matrix deposition phase and the beginning of the mineralization phase. The very high expression level of Bone Sialoprotein confirms the presence of mature osteoblasts, corresponding to the mineralization phase. Finally, this phase was confirmed by the expression of Osteocalcin mRNA, which is designed as the essential marker of the mineralization phase, reaching a maximum expression just before or during tissue mineralization [30]. Therefore, considering our results and the differences in the cell type used, the most important genes involved in the osteogenic differentiation process were constitutively expressed, confirming the matrix deposition and mineralization by hBMSCs cultured and differentiated on DEX-loaded NFMs. The main specific transcription factors involved in the osteogenesis were also quantified by qPCR, namely the core binding factor $\alpha 1$ / runt-related gene (Cbfa1/Runx-2) and Osterix (Osx). Cbfa1/Runx2 was already shown to be involved in the two steps of the differentiation process: driving stem cells into preosteoblasts and also preosteoblasts into osteoblasts. Osterix acts only during the last stage involving the transition preosteoblast/osteoblast $[44,45]$. Our data shows that Osterix and Bone Sialoprotein genes were the bonespecific transcripts with the highest expression levels. Those results further corroborate the successful differentiation of hBMSCs into osteoblasts on DEX-loaded NFMs. Similar osteoblastic gene expression patterns were observed for hBMSCs culture on DEXloaded NFMs under basal conditions. This surprising result corroborates the hypothesis that even a transient exposure of stem cells to DEX (specifically during the 1st week) may be effective in inducing and maintaining the osteoblastic phenotype [24].

\section{Conclusions}

We report herein the development of electrospun biodegradable nanofibers as a release system of an established osteogenic differentiation agent of hBMSCs - dexamethasone. Dexamethasone was incorporated at different concentrations (5, 10, 15 and 20 wt.\% polymer) in the polymeric nanofibers, being the 15 wt.\% release system selected for cell studies because of its sustained release. An increased alkaline phosphatase concentration and deposition of mineralized matrix were observed on dexamethasone releasing nanofibrous system cultured with hBMSCs in dexamethasone-absent osteogenic differentiation medium. The phenotypic and genotypic expression of osteoblasticspecific markers confirmed the osteogenic inducing potential of the loaded growth/differentiation factor. Thus, an osteogenic inductive scaffold was developed aimed for bone tissue engineering strategies.

\section{Acknowledgments}

This work was partially supported by the European Network of Excellence EXPERTISSUES (NMP3-CT-2004-500283). The Portuguese Foundation for Science and Technology was acknowledged for the PhD grant of A. Martins (SFRH/BD/24382/2005).

\section{Appendix}

Figures with essential color discrimination. Figs. 4, 8 and 9 in this article are difficult to interpret in black and white. The full color images can be found in the online version, at doi:10.1016/j. biomaterials.2010.04.010.

\section{References}

[1] Goldberg M, Langer R, Jia XQ. Nanostructured materials for applications in drug delivery and tissue engineering. J Biomater Sci Polym Ed 2007;18 (3):241-68

[2] Venugopal J, Low S, Choon AT, Ramakrishna S. Interaction of cells and nanofiber scaffolds in tissue engineering. J Biomed Mater Res Part B 2008;84 (1):34-48.

[3] Koo OM, Rubinstein I, Onyuksel H. Role of nanotechnology in targeted drug delivery and imaging: a concise review. Nanomedicine 2005;1(3):193-212.

[4] Sill TJ, vonRecum HA. Electrospinning: applications in drug delivery and tissue engineering. Biomaterials 2008;29(13):1989-2006.

[5] Xie JB, Hsieh YL. Ultra-high surface fibrous membranes from electrospinning of natural proteins: casein and lipase enzyme. J Mater Sci 2003;38 (10):2125-33.

[6] Kenawy ER, Bowlin GL, Mansfield K, Layman J, Simpson DG, Sanders EH, et al Release of tetracycline hydrochloride from electrospun poly(ethylene-covinylacetate), poly(lactic acid), and a blend. J Control Release 2002;81 $(1-2): 57-64$

[7] Huang ZM, Zhang YZ, Kotaki M, Ramakrishna S. A review on polymer nanofibers by electrospinning and their applications in nanocomposites. Compos Sci Technol 2003;63(15):2223-53.

[8] Zhang YZ, Su B, Venugopal J, Ramakrishna S, Lim CT. Biomimetic and bioactive nanofibrous scaffolds from electrospun composite nanofibers. Int J Nanomedicine 2007;2(4):623-38.

[9] Maretschek S, Greiner A, Kissel T. Electrospun biodegradable nanofiber nonwovens for controlled release of proteins. J Control Release 2008;127 (2):180-7.

[10] Zeng J, Aigner A, Czubayko F, Kissel T, Wendorff JH, Greiner A. Poly(viny alcohol) nanofibers by electrospinning as a protein delivery system and the retardation of enzyme release by additional polymer coatings. Biomacromolecules 2005;6(3):1484-8.

[11] Townsend-Nicholson A, Jayasinghe SN. Cell electrospinning: a unique biotechnique for encapsulating living organisms for generating active biological microthreads/scaffolds. Biomacromolecules 2006;7(12):3364-9.

[12] Xu X, Chen X, Wang Z, Jing X. Ultrafine PEG-PLA fibers loaded with both paclitaxel and doxorubicin hydrochloride and their in vitro cytotoxicity. Eur Pharm Biopharm 2009;72(1):18-25.

[13] Verreck G, Chun I, Peeters J, Rosenblatt J, Brewster ME. Preparation and characterization of nanofibers containing amorphous drug dispersions generated by electrostatic spinning. Pharm Res 2003;20(5):810-7.

[14] Katti DS, Robinson KW, Ko FK, Laurencin CT. Bioresorbable nanofiber-based systems for wound healing and drug delivery: optimization of fabrication parameters. J Biomed Mater Res Part B 2004;70B(2):286-96.

[15] Dong B, Smith ME, Wnek GE. Encapsulation of multiple biological compounds within a single electrospun fiber. Small 2009;5(13):1508-12.

[16] Sanders EH, Kloefkorn R, Bowlin GL, Simpson DG, Wnek GE. Two-phase electrospinning from a single electrified jet: microencapsulation of aqueous reservoirs in poly(ethylene-co-vinyl acetate) fibers. Macromolecules 2003;36 (11):3803-5.

[17] Chew SY, Wen J, Yim EK, Leong KW. Sustained release of proteins from electrospun biodegradable fibers. Biomacromolecules 2005;6(4):2017-24.

[18] He CL, Huang ZM, Han XJ. Fabrication of drug-loaded electrospun aligned fibrous threads for suture applications. J Biomed Mater Res 2009;89 (1):80-95. 
[19] Jiang H, Hu Y, Li Y, Zhao P, Zhu K, Chen W. A facile technique to prepare biodegradable coaxial electrospun nanofibers for controlled release of bioactive agents. J Control Release 2005;108(2-3):237-43.

[20] Zhang YZ, Wang X, Feng Y, Li J, Lim CT, Ramakrishna S. Coaxial electrospinning of (fluorescein isothiocyanate-conjugated bovine serum albumin)-encapsulated poly(epsilon-caprolactone) nanofibers for sustained release. Biomacromolecules 2006;7(4):1049-57.

[21] Martins A, Araujo JV, Reis RL, Neves NM. Electrospun nanostructured scaffolds for tissue engineering applications. Nanomedicine 2007;2(6):929-42.

[22] Tayalia P, Mooney DJ. Controlled growth factor delivery for tissue engineering. Adv Funct Mater 2009;21:1-17.

[23] Salgado AJ, Oliveira JT, Pedro AJ, Reis RL. Adult stem cells in bone and cartilage tissue engineering. Curr Stem Cell Res Ther 2006;1(3):345-64.

[24] Jaiswal N, Haynesworth SE, Caplan AI, Bruder SP. Osteogenic differentiation of purified, culture-expanded human mesenchymal stem cells in vitro. J Cell Biochem 1997;64(2):295-312.

[25] Li C, Vepari C, Jin HJ, Kim HJ, Kaplan DL. Electrospun silk-BMP-2 scaffolds for bone tissue engineering. Biomaterials 2006;27(16):3115-24.

[26] Nie $\mathrm{H}$, Soh BW, Fu YC, Wang $\mathrm{CH}$. Three-dimensional fibrous PLGA/HAp composite scaffold for BMP-2 delivery. Biotechnol Bioeng 2008;99(1):223-34

[27] Bessa PC, Casal M, Reis RL. Bone morphogenetic proteins in tissue engineering: the road from laboratory to clinic, part II (BMP delivery). J Tissue Eng Regen Med 2008;2(2-3):81-96.

[28] Martins A, Pinho ED, Faria S, Pashkuleva I, Marques AP, Reis RL, et al. Surface modification of electrospun polycaprolactone nanofiber meshes by plasma treatment to enhance biological performance. Small 2009;5(10):1195-206.

[29] Delorme B, Charbord P. Culture and characterization of human bone marrow mesenchymal stem cells. Methods Mol Med 2007;140:67-81.

[30] Venugopal J, Prabhakaran MP, Low S, Choon AT, Zhang YZ, Deepika G, et al. Nanotechnology for nanomedicine and delivery of drugs. Curr Pharm Des 2008;14(22):2184-200.

[31] Balmayor ER, Feichtinger GA, Azevedo HS, van Griensven M, Reis RL. Starchpoly- $\epsilon$-caprolactone microparticles reduce the needed amount of BMP-2. Clin Orthop Relat Res 2009;267(12):3138-48.

[32] Balmayor ER, Tuzlakoglu K, Azevedo HS, Reis RL. Preparation and characterization of starch-poly-epsilon-caprolactone microparticles incorporating bioactive agents for drug delivery and tissue engineering applications. Acta Biomater 2009;5(4):1035-45.
[33] Balmayor ER, Tuzlakoglu K, Marques AP, Azevedo HS, Reis RL. A novel enzymatically-mediated drug delivery carrier for bone tissue engineering applications: combining biodegradable starch-based microparticles and differentiation agents. J Mater Sci Mater Med 2008;19(4):1617-23.

[34] Oliveira JM, Sousa RA, Kotobuki N, Tadokoro M, Hirose M, Mano JF, et al. The osteogenic differentiation of rat bone marrow stromal cells cultured with dexamethasone-loaded carboxymethylchitosan/poly(amidoamine) dendrimer nanoparticles. Biomaterials 2009;30(5):804-13.

[35] Oliveira JM, Kotobuki N, Marques AP, Pirraco RP, Benesch J, Hirose M, et al Surface engineered carboxymethylchitosan/poly(amidoamine) dendrimer nanoparticles for intracellular targeting. Adv Funct Mater 2008;18 (12):1840-53.

[36] Duarte ARC, Mano JF, Reis RL. Dexamethasone-loaded scaffolds prepared by supercritical-assisted phase inversion. Acta Biomater 2009;5(6):2054-62.

[37] Eroglu H, Kas HS, Oner L, Turkoglu OF, Akalan N, Sargon MF, et al. The in-vitro and in-vivo characterization of PLGA:L-PLA microspheres containing dexamethasone sodium phosphate. J Microencapsul 2001;18(5):603-12.

[38] Yoon JJ, Kim JH, Park TG. Dexamethasone-releasing biodegradable polymer scaffolds fabricated by a gas-foaming/salt-leaching method. Biomaterials 2003;24(13):2323-9.

[39] Silva GA, Costa FJ, Neves NM, Coutinho OP, Dias AC, Reis RL. Entrapment ability and release profile of corticosteroids from starch-based microparticles. J Biomed Mater Res 2005;73(2):234-43.

[40] Habibovic P, de Groot K. Osteoinductive biomaterials-properties and relevance in bone repair. J Tissue Eng Regen Med 2007;1(1):25-32.

[41] Abidian MR, Martin DC. Multifunctional nanobiomaterials for neural interfaces. Adv Funct Mater 2009;19(4):573-85.

[42] Beresford JN, Joyner CJ, Devlin C, Triffitt JT. The effects of dexamethasone and 1,25-dihydroxyvitamin D3 on osteogenic differentiation of human marrow stromal cells in vitro. Arch Oral Biol 1994;39(11):941-7.

[43] zur Nieden NI, Kempka G, Ahr HJ. In vitro differentiation of embryonic stem cells into mineralized osteoblasts. Differentiation 2003;71(1):18-27.

[44] Ryoo HM, Lee MH, Kim YJ. Critical molecular switches involved in BMP-2induced osteogenic differentiation of mesenchymal cells. Gene 2006;366 (1):51-7.

[45] Satija NK, Gurudutta GU, Sharma S, Afrin F, Gupta P, Verma YK, et al. Mesenchymal stem cells: molecular targets for tissue engineering. Stem Cells Dev 2007;16(1):7-23. 